\title{
Home range, habitat selection and activity patterns of an arid-zone population of Temminck's ground pangolins, Smutsia temminckii
}

\author{
Darren W. Pietersen ${ }^{1,3^{*}}$, Andrew E. McKechnie' \& Raymond Jansen ${ }^{2,3}$ \\ ${ }^{1}$ Mammal Research Institute, Department of Zoology and Entomology, University of Pretoria, \\ Private Bag X20, Hatfield, 0028 South Africa \\ ${ }^{2}$ Department of Environmental, Water and Earth Sciences, Tshwane University of Technology, \\ Private Bag X680, Pretoria, 0001 South Africa \\ ${ }^{3}$ African Pangolin Working Group \& IUCN Species Survival Commission Pangolin Specialist Group \\ Received 28 January 2014. Accepted 3 September 2014
}

\begin{abstract}
All previous behavioural studies of Temminck's ground pangolins (Smutsia temminckii) have focused on populations in mesic regions. We examined home range size, activity periods, habitat selectivity and refuge site selection of 13 individuals over three years in the Kalahari Desert of South Africa, near the western edge of the species' range. Kernel home ranges of adults averaged $6.5 \pm 5.9 \mathrm{~km}^{2}$, while juveniles had average home ranges of $6.1 \pm 4.0 \mathrm{~km}^{2}$. Reliable prediction of $95 \%$ of the Kernel home range required $88 \pm 67.7$ tracking days. No significant habitat selectivity was observed. Earthen burrows were the most frequently used refuge type. The time at which activity commenced varied seasonally as well as among individuals, with an increase in diurnal activity during winter. Young pangolins also displayed more diurnal activity compared to adults. Individuals spent $5.7 \pm 2.0$ hours per 24-hour cycle outside of refuges, with no significant seasonal variation. Juvenile dispersal peaked during mid-summer, with individuals travelling up to $49 \mathrm{~km}$ from their natal areas. We estimate a breeding density of 0.16 individuals $/ \mathrm{km}^{2}$ and a total density of 0.31 individuals $/ \mathrm{km}^{2}$ for our study area. Our data suggest that activity patterns, movements and refuge selection is similar across the species' southern African range, but that densities may be higher in the Kalahari compared to populations in more mesic eastern areas.
\end{abstract}

Key words: Smutsia temminckii, Manis temminckii, home range, habitat selection, densities.

\section{INTRODUCTION}

Pangolins (Pholidota: Manidae) are unique mammals with bodies covered in hard, keratinous scales rather than hair (Heath \& Coulson 1997a; Richer et al. 1997). There are eight species worldwide, four of which occur in Africa whereas the remaining four species are restricted to the Indomalayan region (Gaudin et al. 2009). Only Temminck's ground pangolin, Smutsia temminckii, occurs in southern Africa, the remaining three Afrotropical species being restricted to forests and forest-savanna mosaics in Central and West Africa (Heath 1992; Gaudin et al. 2009).

Temminck's ground pangolin (hereafter, pangolin) is a seldom-seen, predominantly solitary species (Sweeney 1956) that occurs at low population densities (Sweeney 1956; Heath 1992; Heath \& Coulson 1997a) and is considered rare and threatened (Challender 2011; Challender \& Hywood 2012; Pietersen et al. 2014a). It is widely

\footnotetext{
*Author for correspondence. E-mail: pietersen.darren@gmail.com
}

distributed in savannas and woodlands in southern and East Africa, at latitudes from $29^{\circ} \mathrm{S}$ in South Africa (excluding the central Highveld) northwards to Chad and southern Sudan (Heath 1992; African Pangolin Working Group, unpubl. data). The species is predominantly nocturnal (Wilson 1994; Gaubert 2011) or crepuscular (van Aarde et al. 1990; Jacobsen et al. 1991) although some authors have reported limited diurnal activity (Smithers 1971; Smithers \& Wilson 1979; Coulson 1989; Jacobsen et al. 1991; Swart 1996; Heath \& Coulson 1997a; Richer et al. 1997). Pangolins are entirely myrmecophagous and selective in terms of prey species (Jacobsen et al. 1991; Swart 1996; Richer et al. 1997; Swart et al. 1999; Pietersen 2013) and their distribution is thought to closely mirror that of their ant and termite prey (Swart et al. 1999; Pietersen 2013).

Patterns of circadian activity and home range size vary among studies. Some authors (van Aarde et al. 1990; Jacobsen et al. 1991) report a crepuscular 
peak in activity, while Swart (1996) attributes this apparent peak to observer bias rather than a real increase in activity. Home range size also varies considerably between Zimbabwe (0.2-23.4 km² Heath \& Coulson 1997a) and South Africa (1.3-7.9 km²; van Aarde et al. 1990). There also appears to be variation between sexes, with males having larger home ranges (Heath \& Coulson 1997a).

When inactive, pangolins shelter in abandoned animal burrows, in caves, between rocks or in piles of debris (Jacobsen et al. 1991; Heath 1992; Heath \& Coulson 1997a). Refuges are used predominantly for protection and during parturition (Jacobsen 1991; Swart 1996) although a recent study suggests that burrows may also provide thermally-buffered microclimates facilitating energy savings through reduced costs of thermoregulation (Pietersen 2013).

Temminck's ground pangolin is listed as Vulnerable by the IUCN (Pietersen et al. 2014a) and in light of the growing number of threats facing this species (Pietersen et al. 2014b) it is vitally important to understand its ecological requirements in order to develop a comprehensive conservation management plan. All previous studies of Temminck's ground pangolin have focussed on populations inhabiting mesic savannas in eastern South Africa (van Aarde et al. 1990; Jacobsen et al. 1991; Swart 1996; Swart et al. 1999) and Zimbabwe (Coulson 1989; Heath \& Coulson 1997a,b, 1998; Richer et al. 1997), and data for populations in arid environments are currently lacking.

The aims of this study were to (1) quantify ageand sex-specific variation in pangolin home ranges; (2) determine habitat preference or selectivity; (3) quantify daily and seasonal patterns of activity; (4) determine refuge site preferences; and (5) estimate dispersal ability.

\section{METHODS}

\section{Study site}

Kalahari Oryx Private Game Farm is a 52000 ha farm situated in the Kalahari biome of the Northern Cape Province in South Africa, between latitudes $28^{\circ} 21^{\prime} \mathrm{S}-28^{\circ} 42^{\prime} \mathrm{S}$ and longitudes $21^{\circ} 55^{\prime} \mathrm{E}-$ $22^{\circ} 15^{\prime} \mathrm{E}$ (Fig. 1). The study site is at the arid western edge of the pangolin's distribution in South Africa (Heath 1992; Pietersen et al. 2014a; Fig. 1).

\section{Study animals and telemetry fitting}

Thirteen pangolins were monitored between October 2009 and October 2012, after being located by following fresh tracks or through chance encounters. Once located, a very high frequency (VHF) transmitter (Africa Wildlife Tracking, Pretoria, South Africa) was attached to a single median dorsal scale at the level of the pelvis and secured with two 3-mm machinery bolts and Pratley ${ }^{\circledR}$ Quickset Epoxy. Holes were drilled in the nonvascularized portion of the scale and the bolts inserted from beneath to ensure a flush fit and avoid potential injuries to the animal (van Aarde et al. 1990; Jacobsen et al. 1991; Swart 1996). Animals were not anaesthetized during transmitter attachment as the procedure was of relatively short duration and the non-vascularized portion of the scale lacks nerve endings. The exposed nuts and any gaps between the transmitter and scale were sealed with Pratley ${ }^{\circledR}$ Quickset Putty to prevent vegetation snagging or pangolin mites (Manitherionyssus heterotarsus Vitzthum) sheltering under the transmitter. All pangolins were released at their sites of capture. The VHF transmitters, including the Pratley ${ }^{\circledR}$ Quickset Putty, weighed $100-120$ g, representing $\leq 4 \%$ of body mass.

\section{Spatial data}

Study individuals were located daily or once every three days, and their location recorded with a handheld Global Positioning System (GPS) receiver (GPS V, Garmin, Kansas, U.S.A.) with a stated accuracy of 4-7 m. Focal individuals were followed from the time that they were located until they retired to their refuge for the night to determine diet (Pietersen et al., in prep.). Spatial data were downloaded using DNR Garmin 5.04 software (Minnesota Department of Natural Resources, Minnesota, U.S.A.) and plotted in ArcView GIS 3.2 (Environmental Systems Research Institute, Redlands, California, U.S.A.). Four pangolins were fitted with custom-designed GPS loggers (Ecotone, Poland) to determine fine-scale movements after an initial VHF tracking period of one month suggested that they were resident and unlikely to disperse beyond the study area. The GPS loggers weighed $200 \mathrm{~g}$ each and were only used on individuals weighing more than $6 \mathrm{~kg}$. The GPS loggers were programmed to record locations every hour, taking six locality readings in rapid succession to improve accuracy. GPS logger accuracy was assessed by comparing the logger-recorded localities to coordinates of known locations, which indicated that loggers were accurate to within $20 \mathrm{~m}$, and often to within $\leq 10 \mathrm{~m}$. GPS logger data were downloaded in 


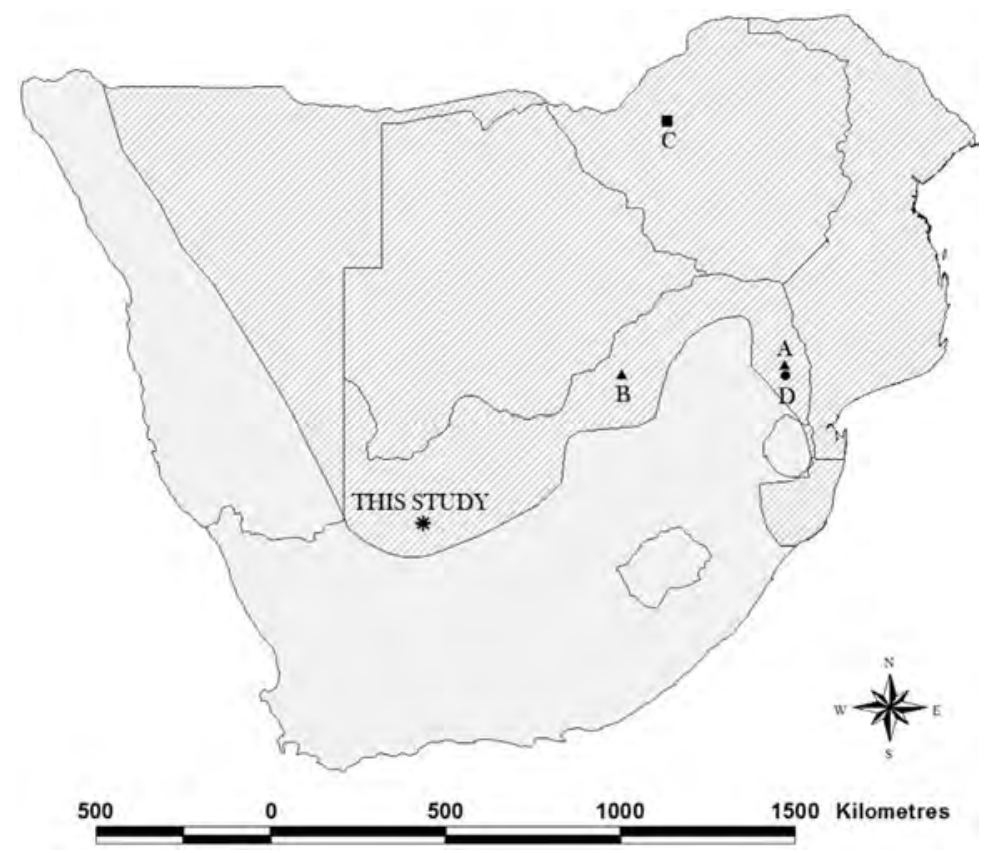

Fig. 1. Location of the present study in relation to previous pangolin research and the distribution of pangolins in southern Africa (shaded region). (A) Hans Hoheison Wildlife Research Station and (B) Thabazimbi: van Aarde et al. (1990), Jacobsen et al. (1991); (C) Sengwa Wildlife Research Station: Heath \& Coulson (1997a,b, 1998), Richer et al. (1997); and (D) Sabi Sand Game Reserve: Swart (1996), Swart et al. (1999).

the field with an Ecotone Remote Download Base Station and transferred to a personal computer.

\section{Home ranges}

GPS logger spatial data were visualized in Google $^{\mathrm{TM}}$ Earth prior to being converted to ArcView format using DNR Garmin 5.04. Outlying records were visually identified and removed prior to analysis and duplicate coordinates removed, so that only one of the six coordinates recorded each hour were retained in order to ensure that no artificial weighting of localities occurred. Spatial data recorded with the handheld GPS did not require editing. Co-ordinates were converted to Universal Transverse Mercator prior to analyses, using the software program Ranges 7 v. 2.9 (Anatrack Ltd., Wareham, U.K.). Three measures of home range were calculated for each individual: Minimum Convex Polygon (MCP), 95\% Harmonic Mean (using default settings) and 95\% Kernel (using default settings). Kernel home range calculations most likely reflect the true home range extent as MCP calculations include all data points, including outliers, and thus do not reflect the core regions most frequently used by the animals (Seaman \& Powell 1996). Likewise,
Harmonic Mean home range estimates are highly sensitive to outlying data points and thus result in the inclusion of many additional grid points (i.e. area) that are not used by the animal (Seaman \& Powell 1996). Hence, both MCP and Harmonic Mean analyses tend to overestimate home range size whereas Kernel analyses are well-defined and more precise and thus provide a better estimate of home range extent (Seaman \& Powell 1996). However, as MCP is the most often used measure of home range size, both $\mathrm{MCP}$ and Kernel home range characteristics were investigated. All values are presented as mean \pm S.D.

Incremental Area Analyses were performed on the Kernel home range data to determine the number of localities required to predict the 95\% core home range, by sequentially adding spatial data to an individual's home range plot and recording the number of records required to predict the core home range. Seasonal differences in home range size were assessed by assigning spatial data for each individual to either the austral summer (November-February) or winter (MayAugust). Data were analysed using GraphPad InStat v 3.0 (GraphPad Software, San Diego, California, U.S.A.). 
Table 1. Vegetation types present on Kalahari Oryx Private Game Farm, classified according to geology and physiognomy. The corresponding Mucina \& Rutherford (2006) vegetation community is indicated.

\begin{tabular}{|c|c|c|}
\hline Vegetation type & Physiognomy & $\begin{array}{l}\text { Mucina \& Rutherford } \\
\text { community(ies) }\end{array}$ \\
\hline Grassy Dwarf Shrubland & $\begin{array}{l}\text { Flat, calcareous plains. Vegetation is of } \\
\text { Karroid origin and }<0.4 \mathrm{~m} \text { in height. A } \\
\text { moderate amount of bare ground, } \\
\text { especially where over-utilized. }\end{array}$ & $\begin{array}{l}\text { Kalahari Karroid Shrubland } \\
\text { (NKb 5) }\end{array}$ \\
\hline Dwarf Karroid Shrubland & $\begin{array}{l}\text { Flat landscape with calcareous soils and } \\
\text { Karroid vegetation that is }<0.5 \mathrm{~m} \text { in height. } \\
\text { There is a preponderance of bare ground. }\end{array}$ & $\begin{array}{l}\text { Gordonia Plains Shrubland } \\
\text { (SVk 16) } \\
\text { Olifantshoek Plains Thornveld } \\
\text { (SVk 13) }\end{array}$ \\
\hline $\begin{array}{l}\text { Acacia mellifera-Rhigozum } \\
\text { trichotomum veld }\end{array}$ & $\begin{array}{l}\text { Flat areas on shallow red sands overlying } \\
\text { calcrete. Moderate clay content resulting in } \\
\text { this being a sweetveld, with concomitant } \\
\text { high levels of overutilization and invasion by } \\
\text { Rhigozum trichotomum. Acacia mellifera is } \\
\text { the dominant tree. }\end{array}$ & $\begin{array}{l}\text { Olifantshoek Plains Thornveld } \\
\text { (SVk 13) } \\
\text { Kalahari Karroid Shrubland } \\
\text { (NKb 5) }\end{array}$ \\
\hline Acacia erioloba veld & $\begin{array}{l}\text { Sandy soils with higher clay content, typi- } \\
\text { cally at the base of mountains. Trees vary } \\
\text { from } 2-6 \mathrm{~m} \text { in height, with medium to high } \\
\text { grass cover. Dominated by Acacia erioloba. }\end{array}$ & $\begin{array}{l}\text { Olifantshoek Plains Thornveld } \\
\text { (SVk 13) }\end{array}$ \\
\hline Acacia mellifera thickets & $\begin{array}{l}\text { Dense to open Acacia mellifera savanna } \\
\text { with moderate grass cover on sandy soils } \\
\text { with intermediate clay content. Typically } \\
\text { found between Acacia erioloba veld and } \\
\text { mixed savanna. }\end{array}$ & $\begin{array}{l}\text { Gordonia Duneveld } \\
\text { (SVkd 1) } \\
\text { Olifantshoek Plains Thornveld } \\
\text { (SVk 13) }\end{array}$ \\
\hline Acacia haematoxylon savanna & $\begin{array}{l}\text { Undulating duneveld on sandy soils. Low } \\
\text { tree density and high grass cover; trees } \\
\text { usually } 2-3 \mathrm{~m} \text { in height. Acacia haema- } \\
\text { toxylon is normally the only tree in this } \\
\text { landscape. }\end{array}$ & $\begin{array}{l}\text { Gordonia Duneveld } \\
\text { (SVkd 1) } \\
\text { Olifantshoek Plains Thornveld } \\
\text { (SVk 13) }\end{array}$ \\
\hline Mixed savanna & $\begin{array}{l}\text { Undulating duneveld with a high proportion } \\
\text { of grass cover and moderate levels of tree } \\
\text { and shrub cover. Various tree and shrub } \\
\text { species dominate, including Boscia } \\
\text { albitrunca, Acacia mellifera, Acacia erioloba, } \\
\text { Acacia haematoxylon, Grewia flava and } \\
\text { Ziziphus mucronata. }\end{array}$ & $\begin{array}{l}\text { Gordonia Duneveld } \\
\text { (SVkd 1) } \\
\text { Olifantshoek Plains Thornveld } \\
\text { (SVk 13) }\end{array}$ \\
\hline Duneveld grassland & $\begin{array}{l}\text { Flat to undulating duneveld on sandy soils, } \\
\text { nearly devoid of trees and shrubs. }\end{array}$ & $\begin{array}{l}\text { Gordonia Duneveld } \\
\text { (SVkd 1) }\end{array}$ \\
\hline Mountain Veld & $\begin{array}{l}\text { The most diverse vegetation type, restricted } \\
\text { to rocky ridges and mountains. Clay content } \\
\text { is high. Rock cover is high ( } 50-60 \%) \text { and } \\
\text { vegetation cover between rocks is nearly } \\
\text { absolute. }\end{array}$ & $\begin{array}{l}\text { Koranna-Langeberg Mountain } \\
\text { Bushveld } \\
\text { (SVk 15) }\end{array}$ \\
\hline
\end{tabular}

\section{Habitat selectivity}

Vegetation at the study site was categorized into nine types based on dominant plant species, structure and geology (Table 1). Habitat selectivity was quantified with a modified selectivity index $S$ (McNaughton 1978):

$$
S_{j}=\Sigma\left|P_{\mathrm{Hi}}-P_{\mathrm{Li}}\right| / 2
$$

where $P_{\mathrm{Hi}}$ is the proportional abundance of the $i$-th habitat in the study area and $P_{\mathrm{Li}}$ is the proportional abundance of locality records in the $i$-th habitat for pangolin $j$. An $S$-value of zero denotes no habitat 
selectivity, whereas a value of 1.0 denotes maximum habitat selectivity. Seasonal differences in habitat selection were assessed by assigning an individual's spatial data to either the austral summer (November-February) or winter (MayAugust).

\section{Duration of activity and emergence times}

The times at which pangolins emerged from and returned to their refuges were determined for three individuals fitted with GPS loggers. The loggers were able to record geographic locations only when above ground, and thus the first recorded position for each day occurred within one hour of the study animal emerging. The loggers provided an unbiased record of emergence and return times as data were recorded in the same manner for all individuals and were not influenced by the presence of an observer. Because locations were recorded hourly, emergence times were likewise assigned to 1-hour bins based on the 24-hour clock (00:00 represents 00:00-00:59, 01:00 represents 01:00-01:59, etc.). When study animals rested in exposed sites continuous hourly data collection continued, these data being discernable as a cluster of successive points confined to a very small area. In these instances the earliest datum in the cluster was regarded as the return time of the previous day and the first datum outside of this cluster was considered the emergence time of the following day. Mean duration of activity (the time spent out of the refuge within each 24-hour cycle) was calculated from the time between emergence and return. Multiple regression analysis was performed on the emergence times using GraphPad InStat v 3.0 to determine whether emergence time was affected by ambient air temperature.

\section{Refuge sites}

Study animals were regularly located while inactive, or followed until they entered a refuge at the end of a foraging bout. The location and nature of each refuge was recorded using a handheld GPS unit. Refuges that were re-used by the same or different individual on subsequent occasions were recorded as such.

\section{RESULTS}

\section{Home ranges}

Home ranges were estimated for seven adult $(\geq 6 \mathrm{~kg}$ ) and six juvenile $(<6 \mathrm{~kg})$ pangolins, of which two and three individuals, respectively, had fewer than 50 locations each and were excluded from statistical analyses. Home range size varied depending on the length, and hence age, of individuals (Table 2). Mean MCP and Kernel home ranges for adults (males and females combined) were $10.0 \pm 8.9 \mathrm{~km}^{2}$ and $6.5 \pm 5.9 \mathrm{~km}^{2}$, respectively, whereas juveniles (both sexes combined) had smaller mean MCP and Kernel home ranges of $7.1 \pm 1.1 \mathrm{~km}^{2}$ and $6.1 \pm 4.0 \mathrm{~km}^{2}$, respectively. The degree of home range overlap could be determined for two adult pairs: the respective home ranges of STEM 22 and STEM 35 overlapped by $12.7 \%$, while the home range of adult male STEM 38 was entirely encompassed by the home range of adult female STEM 5.

Only two adult individuals (STEM 5 and STEM 38) had sufficient locality data to compare seasonal differences in home range size. Seasonal trends in these two individuals were opposite in direction, with the female using a larger area in summer and the male using a larger area in winter (Fig. 2).

The incremental area analysis indicated that four adult and two juvenile pangolins had additive home range graphs that reached a plateau, suggesting that additional points were unlikely to significantly alter the estimated home range size. Analysis of these data indicated that $88 \pm 67.7$ locations (i.e. tracking days) were required to predict $95 \%$ of the Kernel home range at this study site.

\section{Densities}

The maximum kernel home range sizes of adult male and female pangolins at the study site were $11.91 \mathrm{~km}^{2}$ and $13.76 \mathrm{~km}^{2}$, respectively. Thus the average maximum home range size for a pair of pangolins was $12.8 \mathrm{~km}^{2}$, suggesting a density of 0.16 reproductively active adult individuals $/ \mathrm{km}^{2}$. In addition to the breeding pair, each home range also supported the most recent offspring. Field observations also suggested that each home range regularly supported a transient individual, although the period that it remained within the home range varied considerably and could not always be reliably determined. Thus the overall density of pangolins at the study site was approximately 0.23 individuals $/ \mathrm{km}^{2}$ (including offspring) but may be as high as 0.31 individu$\mathrm{als} / \mathrm{km}^{2}$ if transient individuals are included.

\section{Habitat selectivity}

An analysis of five adult and six juvenile pangolins' home ranges indicated that there was no apparent habitat selectivity (Table 3 ). Only one 


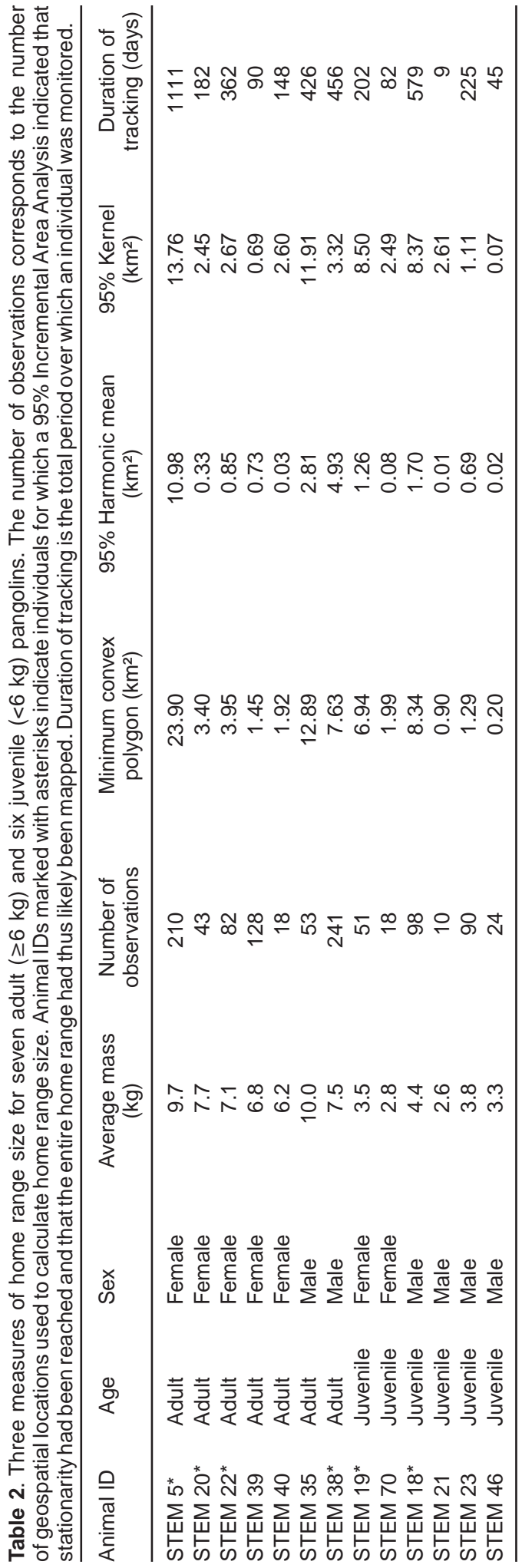

adult male (STEM 38) and one adult female (STEM 5) had sufficient locality data to investigate seasonal differences in habitat selectivity, with neither individual showing any seasonal preferences (Table 3).

\section{Duration of activity}

Emergence and return times from refuges (Fig. 3) varied among individuals and across seasons. There was a tendency for earlier emergence times in winter compared to summer, with a concomitant increase in the proportion of diurnal activity during winter. Juveniles were also observed to be more prone to diurnal activity than adults, whereas both age classes were more diurnal during cold weather. Emergence time was highly dependent on air temperature, with minimum temperature $(t=2.701, P=0.008$, d.f. $=175)$ a statistically stronger predictor than maximum temperature $(t=2.121, P=0.035$, d.f. $=175)$. Emergence times were unaffected by the lunar cycle (data not shown).

The mean daily duration of activity was $5.7 \pm$ 2.0 hours, ranging from $1-12$ hours. The total duration of activity did not differ between winter and summer, although individuals typically became active earlier in winter. Mean winter daily foraging periods were $5.6 \pm 1.6$ hours (range $2-10$ hours) whereas mean summer foraging periods were $5.7 \pm 2.2$ hours (range 1-12 hours).

\section{Refuge sites}

Pangolins were recorded using refuges on 492 occasions during this study (Table 4). Burrows, especially those excavated by aardvark (Orycteropus afer), were the most favoured refuge type $(89.8 \%, n=442)$. Only juvenile pangolins used vegetation as cover and were also more likely to take refuge among rocks. Only one adult, a dispersing male (STEM 31), was observed excavating its own burrow, which was $<1 \mathrm{~m}$ in depth. Refuge selection did not differ significantly between adults and juveniles (Student's t-test $t=0.005, P=$ 1.0 , d.f. $=7$ ).

\section{Dispersal}

Dispersal was defined as young animals leaving their natal home range without returning to it within the study period, or older individuals that were not resident in any particular area indicating that they had no fixed home range. Four individuals were observed dispersing during this study. A young female (STEM 19, $3.5 \mathrm{~kg}$ ) that was tagged in 


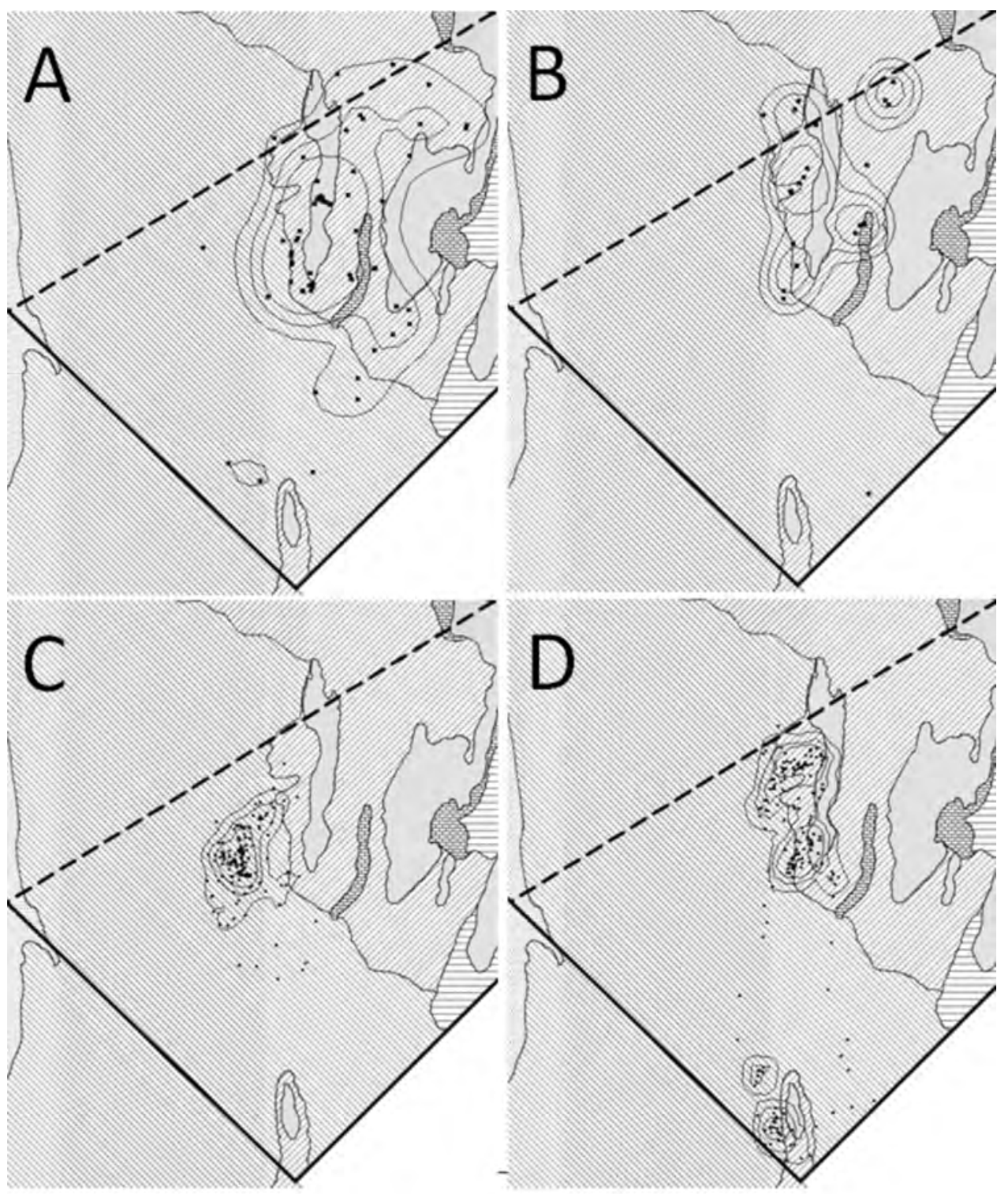

Vegetation types

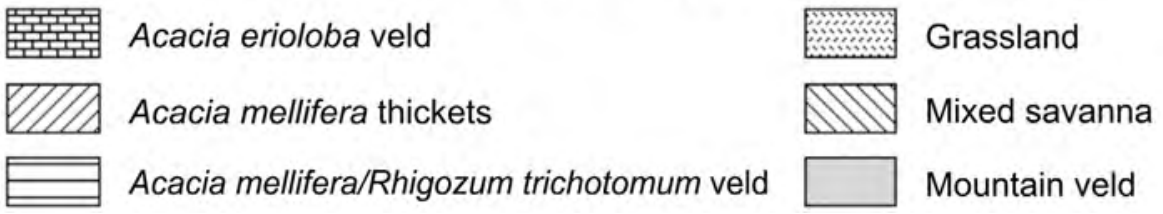

Fig. 2. Summer (Nov-Feb) and winter (May-Aug) home ranges for an adult female (STEM 5) and adult male (STEM 38) pangolin on Kalahari Oryx Private Game Farm. A, STEM 5 summer home range ( $n=61$ observations); B, STEM 5 winter home range ( $n=24$ observations); C, STEM 38 summer home range ( $n=154$ observations); D, STEM 38 winter home range ( $n=210$ observations). The 50th, 75th and 95th percentile Kernel home ranges are displayed for each season. Solid dark lines show electrified game-proof fences; the dashed dark line indicates an electrified fence that was removed during this study. 
Table 3. Habitat selectivity values for 12 pangolins on Kalahari Oryx Private Game Farm. A value of zero represents no habitat selectivity, whereas a value of one represents maximum habitat selectivity.

\begin{tabular}{lccc}
\hline Animal ID & Overall selectivity & Summer & Winter \\
\hline STEM 35 & 0.122 & - & - \\
STEM 5* & 0.182 & 0.164 & 0.247 \\
STEM 20* & 0.155 & - & - \\
STEM 38* & 0.075 & 0.067 & 0.142 \\
STEM 22* & 0.142 & - & - \\
STEM 39 & 0.370 & - & - \\
STEM 18* & 0.322 & - & - \\
STEM 23 & 0.068 & - & - \\
STEM 19* & 0.122 & - & - \\
STEM 46 & 0.046 & - & - \\
STEM 70 & 0.203 & & - \\
STEM 21 & 0.330 & & - \\
Overall & 0.081 & & - \\
\hline
\end{tabular}

her natal home range remained in this area for six months (28 June 2010 - 30 December 2010) before starting to disperse. She moved $36 \mathrm{~km}$ in 11 days before contact was lost, before being detected again nine months later $24.5 \mathrm{~km}$ northeast of her natal home range and $17.5 \mathrm{~km}$ southeast of her last known location, where anecdotal evidence suggests that she had been present since September 2011. In total she travelled a minimum distance of $48.5 \mathrm{~km}$ in eight months. A young male (STEM $23,3.8 \mathrm{~kg}$ ) was tracked for four months in his natal home range before he started dispersing during December 2010. He appeared to establish a small home range $5 \mathrm{~km}$ north of his natal home range before contact was lost, presumably due to him leaving the area. A young adult male (STEM 47, $6.7 \mathrm{~kg}$ ) was located within the home range of female STEM 5 and remained in this area for a month before starting to disperse on 6 October 2011, covering at least $32 \mathrm{~km}$ in 20 days. Another young adult male (STEM 31, $6.5 \mathrm{~kg}$ ) was tracked for 18 days between 22 December 2010 and 11 January 2011 before contact was lost. During this time he moved $81 \mathrm{~km}$ in an area of $154 \mathrm{~km}^{2}(\mathrm{MCP})$, but in no consistent direction.

\section{DISCUSSION}

A home range is broadly defined as the minimum area required by an individual to obtain adequate resources such as food, shelter and breeding opportunities, but excludes cases of vagrancy or exploratory sallies (Burt 1943; Fielden 1991). This study confirms that $S$. temminckii does indeed have a clearly defined home range and our find-

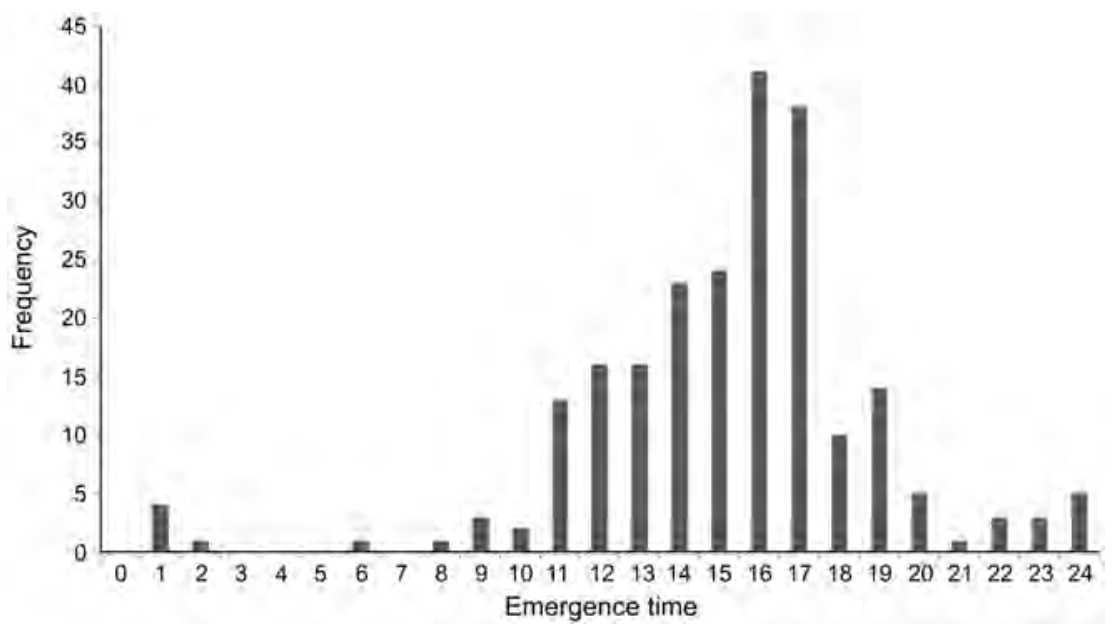

Fig. 3. Pooled emergence times of two adult males and a young adult female pangolin fitted with GPS loggers at Kalahari Oryx Private Game Farm. Emergence times are divided into 1-hour intervals according to the 24-hour clock. 
Table 4. Nature and proportion of refuges used by 13 pangolins on Kalahari Oryx Private Game Farm between September 2009 and October 2012. $n=$ number of times pangolins used each refuge type, $\%=$ proportional use of each refuge type.

\begin{tabular}{|c|c|c|c|c|c|c|}
\hline \multirow[b]{2}{*}{ Refuge type } & \multicolumn{2}{|c|}{ Overall } & \multicolumn{2}{|c|}{ Adults } & \multicolumn{2}{|c|}{ Juveniles } \\
\hline & $n$ & $\%$ & $n$ & $\%$ & $n$ & $\%$ \\
\hline Aardvark burrow & 343 & 69.7 & 237 & 74.8 & 106 & 60.6 \\
\hline Springhare warren & 68 & 13.8 & 48 & 15.1 & 20 & 11.4 \\
\hline Cave & 32 & 6.5 & 15 & 4.7 & 17 & 9.7 \\
\hline Porcupine warren & 30 & 6.1 & 13 & 4.1 & 17 & 9.7 \\
\hline Rocks & 13 & 2.6 & 2 & 0.6 & 11 & 6.3 \\
\hline Vegetation & 3 & 0.6 & 0 & 0 & 3 & 1.7 \\
\hline Termite mound & 2 & 0.4 & 1 & 0.3 & 1 & 0.6 \\
\hline Self-excavated burrow & 1 & 0.2 & 1 & 0.3 & 0 & 0 \\
\hline Total & 492 & & 317 & & 175 & \\
\hline
\end{tabular}

ings are similar to studies on the same species in Zimbabwe (Heath \& Coulson 1997a) but are larger than the data published on individuals in northeastern South Africa (van Aarde et al. 1990). The latter study involved following five individuals over 52 monitoring nights, and the small home ranges recorded in that study can be attributed to the shorter duration of the study. Our estimate of $88 \pm 67.7$ tracking days being required to predict an individual's core home range is similar to the corresponding value of Heath \& Coulson (1997a), although the large standard deviation of our mean value suggests that substantially more observations may sometimes be required. The large standard deviation could be as a result of the relatively small sample size, and this should be further investigated in future studies.

Habitat selection can be broadly defined as the process by which a species chooses between the available resources and this, in turn, can have implications on its behaviour (Johnson 1980). The lack of habitat selectivity at our study site contrasts with the high selectivity recorded by Swart (1996) in the eastern savanna of South Africa. One possible explanation concerns the uniform geology and climate at the Kalahari study site (Mucina \& Rutherford 2006) presumably resulting in a fairly uniform ant community (Pietersen 2013; Pietersen et al., in prep.). As prey availability is one of the major driving forces behind habitat selection (Langvatn \& Hanley 1993; Storch 1993; Alcala-Galvan \& Krausman 2013), this uniformity probably invalidates habitat selection as there would be no energetic gain in selecting specific habitats if all have similar prey communities (Langvatn \& Hanley 1993; Edwards et al. 2002). This lack of selectivity may also be attributable to the individual vegetation types in the Kalahari being more extensive than those in Swart's (1996) study (Mucina \& Rutherford 2006), with individual home ranges thus incorporating fewer vegetation types. Our data also suggest that pangolins used their entire home range continuously, moving between successive refuges on an ad hoc basis, and that home ranges are stable across successive years. This pattern is similar to the findings of Heath \& Coulson (1997a) but contrasts with those of van Aarde et al. (1990) who suspected that although pangolins have a home range of c. 20 $\mathrm{km}^{2}$, they only use a small portion for periods of up to three months at a time before moving to a different, often adjoining, portion.

Animals in arid environments typically have larger home ranges than their conspecifics in higher rainfall areas (Mares et al. 1982; Attuquayefio et al. 1986; Fielden 1991; Alcala-Galvan \& Krausman 2013), possibly due to lower primary productivity in xeric environments resulting in fewer available food resources (Fielden 1991; Alcala-Galvan \& Krausman 2013). However, pangolins in the Kalahari are 25-30\% smaller than individuals from northeastern South Africa and Zimbabwe (D.W. Pietersen, unpubl. data) and smaller individuals tend to have smaller home ranges than do larger individuals of the same species (Mohr 1947; McNab 1963). We speculate that the lack of variation in home range size across an aridity gradient reflects the interacting effects of variation in body size (i.e. smaller in the arid west, with an expectation of smaller home ranges) and primary productivity (lower in the arid west with an expectation of larger home ranges). According to this notion, the differences in body mass and primary productivity effectively cancel 
each other, resulting in similar home range sizes across the species' southern African range.

The comparatively large difference between $\mathrm{MCP}$ and Kernel home range estimates for adults, and the relatively small difference between these estimates for juveniles, likely reflects differences in statistical approaches and the relatively small sample sizes. Adults appear to be more prone to exploratory wanderings than juveniles, occasionally wandering outside of the core home range for short periods, which results in more outlying data points. Juveniles, by comparison, tend to initially accompany an adult while foraging, thus obtaining knowledge of the core home range and later wandering within this core area (prior to dispersal). This apparent concentration on the core area by juveniles may be as a result of familiarity, particularly with regards to refuge locations and prey distribution. All juvenile pangolins fitted with telemetry during this study initially established home ranges within their natal home range before subsequently dispersing. These results concur with those of Heath \& Coulson (1997a) who recorded a newly weaned pup initially establishing its home range within its natal home range and suspected that juvenile dispersal would occur at a later stage. Pangolins are probably able to disperse much further than the $49 \mathrm{~km}$ and $154 \mathrm{~km}^{2}$ (MCP) recorded during this study as van Aarde et al. (1990) report a young male travelling $300 \mathrm{~km}$ in four months, suggesting extensive dispersal with consequent implications for recolonization and gene flow. Our data also suggest that male pangolins may disperse further than females and may also remain rovers (reproductively mature adults without a fixed home range) for longer.

Heath \& Coulson (1997a) recorded a male pangolin's home range overlapping with those of a number of females, suggesting a polygynous mating system (see also Gaubert 2011). This is contrary to our findings, where home ranges of territorial adult males closely mirrored those of adult females, suggesting a single pair of sexually mature adults in each home range. Furthermore, no movements of males into adjoining females' home ranges were observed, except for roving males. These divergent results could conceivably arise from previous authors overlooking the presence of roving males whose presence within a given home range is transient. Further studies are required to assess whether roving males actively engage in reproduction (i.e. a polygynous mating system), or whether they are transient without any reproductive input (i.e. a monogamous mating system).

Swart (2013) estimated a breeding density of 0.12 individuals $/ \mathrm{km}^{2}$ and total density of 0.24 individu$\mathrm{als} / \mathrm{km}^{2}$ for $\mathrm{S}$. temminckii in eastern South Africa. Both our breeding density and total density estimates exceed these estimates, suggesting a higher pangolin density in the Kalahari biome. This is supported by the higher sighting frequency in the Kalahari (D.W. Pietersen, unpubl. data). Heath \& Coulson (1997a) did not calculate densities, but using their MCP home range values a total density of 0.11 individuals $/ \mathrm{km}^{2}$ is obtained, substantially lower than both South African density estimates and possibly reflects variation in study design rather than true density differences. Further research is required to verify this possibility. The aforementioned densities are below the average density of $1.0 \pm 0.3$ individuals $/ \mathrm{km}^{2}$ that has been calculated for thick-tailed pangolins (Manis crassicaudata) in Pakistan (Mahmood et al. 2014).

The average duration of activity we observed is comparable to previously reported values (Jacobsen et al. 1991; Swart 1996; Heath \& Coulson 1997b), and our data support Swart's (1996) finding of no seasonal differences in the duration of activity, although the onset of activity varied seasonally as well as with the age class of the individual, while weather conditions also had an impact. Our data also support Swart's (1996) assertion that the apparent increase in crepuscular pangolin activity reflects an increase in observer effort rather than a true effect. Compared to the findings of Swart (1996) and Richer et al. (1997), we recorded a higher proportion of diurnal activity in all age classes. This increased diurnal activity in the Kalahari is likely due to the more extreme climate within this region. Pangolin scales provide little thermal insulation (McNab 1984; Heath \& Hammel 1986; Weber et al. 1986) and body temperature is atypically variable (D.W. Pietersen, A.E. McKechnie and R. Jansen, unpubl. data) and it may be that behavioural avoidance of low environmental temperatures is an important component of thermoregulation in this species. Moreover, winter is a nutritionally stressful time as ant activity decreases and more energy is expended to maintain a constant body temperature (Swart 1996; Pietersen 2013). By becoming more diurnal during winter, pangolins are able to avoid nocturnal activity and the associated low air temperatures, thereby conserving energy. Conversely, by being nocturnal during summer indi- 
viduals are able to avoid the extreme daytime temperatures, thus conserving water that would otherwise be required for evaporative cooling. As ant activity remains consistently low during winter regardless of the diel cycle (Pietersen 2013), pangolins probably do not take prey activity cycles into consideration during this time.

Aardvark burrows were the most frequently used refuges, although other burrows, caves and rock piles were also opportunistically used. Most records of individuals using exposed refuges were juveniles or dispersing individuals, possibly reflecting juveniles lacking an intimate knowledge of their home range, or individuals finding themselves in unfamiliar surroundings during dispersal. Van Aarde et al. (1990) reported individuals returning to the same burrow every 3-5 nights. During our study, the length of time that an individual occupied any particular burrow varied from one to $c .30$ nights and new burrows were continuously added and old burrows abandoned as burrows collapsed and new ones created through the digging actions of other species.

Our results suggest that many of the ecological traits are similar between pangolin populations living in arid and mesic environments, although further studies within a variety of ecosystems are required to justify this. This study further suggests that pangolin densities may be higher in the Kalahari than they are in eastern South Africa and Zimbabwe, which may have conservation implications. The reasons for this purported higher density require further investigation, but may reflect a higher prey density. Our data also suggest that individuals of a species in arid environments do not necessarily have larger home ranges than do conspecifics in mesic regions, but that morphology may also play a role in determining home range size. The data suggest that most dispersal events occur over relatively short distances but that larger dispersal events, especially by young males, may occasionally occur. Despite being the largest study to date of Temminck's ground pangolin, our sample size remains small for some aspects and this limits extrapolation of some of the results to the broader pangolin population.

\section{ACKNOWLEDGEMENTS}

Kalahari Oryx Private Game Farm, its owner and managers are thanked for allowing this research to be undertaken on their property. Financial support for this project was received from the National Research Foundation (grant 71454), the
Mohamed bin Zayed Species Conservation Fund (project 0925713), Tshwane University of Technology and University of Pretoria. Piet Stapleton, Simon Motene, Isak van Wyk, Tanda Lolwana, Falakhe Zulu, Joseph Ogies, Eddie Dikolanyane, Martiens Coetzee, Errol Pietersen, Ryan Pietersen, Michèle Pietersen, Chené Barnard, Dada Vries, Mario Titus, Attie Koopman, Jan Moos, Frank Hoorniet, Jan Markus and Ricard Titus are thanked for their assistance in the field. Crawford Joubert, Marieta Booysen, Theuns Strauss, Sampie de Beer, Klaas Jacobs, Willem Strauss, Koos Booysen, Pieter Slabbert, Fanie Maritz, Sakkie van Staden, Sarel Saunderson, Frans Verdoes, Nico Steyn, Louis Steyn and Maans Gousaard are thanked for granting permission to follow dispersing animals across their farms and for their hospitality. The Bateleurs, in particular Jannie Visser and Andrew Colby, are gratefully acknowledged for assisting with flight time to locate dispersing individuals. Niels Jacobsen and Errol Pietersen are thanked for providing access to their raw data. This research was conducted under research permits FAUNA 767/2009, FAUNA 016/2010, FAUNA $806 / 2010$ and FAUNA $082 / 2012$ issued by the Northern Cape Department of Environment and Nature Conservation, for which we are grateful. This research was approved by the University of Pretoria Animal Use and Care (Ethics) Committee, reference no. EC055-09. Theresa C. Wossler and three anonymous reviewers are thanked for greatly improving earlier drafts of this manuscript.

\section{REFERENCES}

ALCALA-GALVAN, C.H. \& KRAUSMAN, P.R. 2013. Home range and habitat use by desert mule deer in altered habitats. California Fish and Game 99(2): 65-79.

ATTUQUAYEFIO, D.K., GORMAN, M.L. \& WOLTON, R.J. 1986. Home range sizes in the wood mouse Apodemus sylvaticus: habitat, sex and seasonal differences. Journal of Zoology (London) 210: 45-53.

BURT, W.H. 1943. Territoriality and home range concepts as applied to mammals. Journal of Mammalogy 24: 346-359.

CHALLENDER, D.W.S. 2011. Asian pangolins: increasing affluence driving hunting pressure. TRAFFIC Bulletin 23(3): 92-93.

CHALLENDER, D.W.S. \& HYWOOD, L. 2012. African pangolins under increased pressure from poaching and intercontinental trade. TRAFFIC Bulletin 24(2): 53-55.

COULSON, M.H. 1989. The pangolin (Manis temminckii Smuts, 1832) in Zimbabwe. African Journal of Ecology 27: 149-155.

EDWARDS, G.P., DE PREU, N., CREALY, I.V. \& SHAKESHAFT, B.J. 2002. Habitat selection by feral 
cats and dingoes in a semi-arid woodland environment in central Australia. Austral Ecology 27: 26-31.

FIELDEN, L.J. 1991. Home range and movements of the Namib Desert golden mole, Eremitalpa granti namibensis (Chrysochloridae). Journal of Zoology (London) 223: 675-686.

GAUBERT, P. 2011. Family Manidae (Pangolins). In: Handbook of the Mammals of the World, Vol. 2: Hoofed Mammals, (eds) D.E. Wilson \& R.A. Mittermeier, pp. 82-103. Lynx Edicions, Barcelona, Spain.

GAUDIN, T.J., EMRY, R.J. \& WIBLE, J.R. 2009. The phylogeny of living and extinct pangolins (Mammalia, Pholidota) and associated taxa: a morphology based analysis. Journal of Mammalian Evolution 16: 235-305.

HEATH, M.E. 1992. Manis temminckii. Mammalian Species 415: $1-5$.

HEATH, M.E. \& COULSON, I.M. 1997a. Home range size and distribution in a wild population of Cape pangolins, Manis temminckii, in north-west Zimbabwe. African Journal of Ecology 35: 94-109.

HEATH, M.E. \& COULSON, I.M. 1997b. Preliminary studies on relocation of Cape pangolins Manis temminckii. South African Journal of Wildlife Research 27: 51-56.

HEATH, M.E. \& COULSON, I.M. 1998. Measurements of length and mass in a wild population of Cape pangolins (Manis temminckii) in north-west Zimbabwe. African Journal of Ecology 36: 267-270.

HEATH, M.E. \& HAMMEL, H.T. 1986. Body temperature and rate of $\mathrm{O}_{2}$ consumption in Chinese pangolins. American Journal of Physiology - Regulatory, Integrative and Comparative Physiology 250: 377-382.

JACOBSEN, N.H.G., NEWBERY, R.E., DE WET, M.J., VILJOEN, P.C. \& PIETERSEN, E. 1991. A contribution of the ecology of the Steppe Pangolin Manis temminckii in the Transvaal. Zeitschrift für Säugetierkunde 56(2): 94-100.

JOHNSON, D.H. 1980. The comparison of usage and availability measurements for evaluating resource preference. Ecology 61: 65-71.

LANGVATN, R. \& HANLEY, T.A. 1993. Feeding-patch choice by red deer in relation to foraging efficiency. Oecologia 95: 164-170.

MAHMOOD, T., IRSHAD, N. \& HUSSAIN, R. 2014. Habitat preference and population estimates of Indian pangolin (Manis crassicaudata) in District Chakwal of Potohar Plateau, Pakistan. Russian Journal of Ecology 45: 70-75.

MARES, M.A., LACHER, T.E., WILLIG, M.R., BITAR, N.A., ADAMS, R., KLINGER, A \& TAZIK, D. 1982. An experimental analysis of social spacing in Tamias striatus. Ecology 63: 267-273.

McNAB, B.K. 1963. Bioenergetics and determination of home range size. American Naturalist 97: 133-139.

McNAB, B.K. 1984. Physiological convergence amongst ant-eating and termite-eating mammals. Journal of Zoology (London) 203: 485-510.

McNAUGHTON, S.J. 1978. Serengeti ungulates: feeding selectivity influences the effectiveness of plant defence guilds. Science 199: 806-807.

MOHR, C.O. 1947. Table of equivalent populations of North American mammals. American Midland Naturalist 37: 223-249.

MUCINA, L. \& RUTHERFORD, M.C. (eds). 2006. The vegetation of South Africa, Lesotho and Swaziland. Strelitzia 19. South African National Biodiversity Institute, Pretoria, South Africa.

PIETERSEN, D.W. 2013. Behavioural ecology and conservation biology of ground pangolins (Smutsia temminckii) in the Kalahari Desert. M.Sc. thesis, University of Pretoria, Pretoria, South Africa.

PIETERSEN, D., WATERMAN, C., HYWOOD, L., RANKIN, P. \& SOEWU, D. 2014a. Smutsia temminckii. In: IUCN 2014. The IUCN Red List of threatened species, Version 2014.2. Online at: www.iucnredlist.org. (accessed 1 September 2014).

PIETERSEN, D.W., McKECHNIE, A.E. \& JANSEN, R. $2014 \mathrm{~b}$. A review of the anthropogenic threats faced by Temminck's ground pangolin, Smutsia temminckii, in southern Africa. South African Journal of Wildlife Research 44(2): 167-178.

RICHER, R., COULSON, I. \& HEATH, M. 1997. Foraging behaviour and ecology of the Cape pangolin (Manis temminckii) in north-western Zimbabwe. African Journal of Ecology 35: 361-369.

SEAMAN, D.E. \& POWELL, R.A. 1996. An evaluation of the accuracy of kernel density estimators for home range analysis. Ecology 77(7): 2075-2085.

SMITHERS, R.H.N. 1971. The mammals of Botswana. Museum Memoirs of the National Museums and Monuments, Rhodesia 4: 1-340.

SMITHERS, R.H.N. \& WILSON, V.J. 1979. Check List and Atlas of the Mammals of Zimbabwe Rhodesia. Museum Memoir no. 9. The Trustees of the National Museums and Monuments, Salisbury, Zimbabwe Rhodesia.

STORCH, I. 1993. Habitat selection by capercaillie in summer and autumn: is bilberry important? Oecologia 95: 257-265.

SWART, J. 1996. Foraging behaviour of the Cape pangolin Manis temminckii in the Sabi Sand Wildtuin. M.Sc. thesis, University of Pretoria, Pretoria, South Africa.

SWART, J. 2013. Smutsia temminckii Ground pangolin (Temminck's ground pangolin, Cape pangolin). In: Mammals of Africa Volume 5: Carnivores, Pangolins Equids and Rhinoceroses, (eds) J. Kingdon \& M. Hoffmann, pp. 400-405. Bloomsbury Natural History, London.

SWART, J.M., RICHARDSON, P.R.K. \& FERGUSON, J.W.H. 1999. Ecological factors affecting the feeding behaviour of pangolins (Manis temminckii). Journal of Zoology 247: 281-292.

SWEENEY, R.C.H. 1956. Some notes on the feeding habits of the ground pangolin, Smutsia temminckii (Smuts). Annual Magazine of Natural History, 12th ser. 9: 893-896.

VAN AARDE, R.J., RICHARDSON, P.R.K. \& PIETERSEN, E. 1990. Report on the behavioural ecology of the Cape Pangolin (Manis temminckii). Mammal Research Institute, University of Pretoria, Internal Report.

WEBER, R.E., HEATH, M.E. \& WHITE, F.N. 1986. Oxygen binding functions of blood and hemoglobin from the Chinese pangolin, Manis pentadactyla: possible implications of burrowing and low body temperature. Respiration Physiology 64: 103-112.

WILSON, A.E. 1994. Husbandry of pangolins. International Zoo Yearbook 33: 248-251. 